\title{
The Effects of M100907 in Pharmacological and Developmental Animal Models of Prepulse Inhibition Deficits in Schizophrenia
}

Mark A. Geyer, Ph.D., Kirsten Krebs-Thomson, Ph.D., and Geoffrey B. Varty, Ph.D.

Patients with schizophrenia exhibit deficits in an operational measure of sensorimotor gating: prepulse inhibition (PPI) of the startle response. M100907, a selective 5-HT $2 \mathrm{~T}_{2}$-receptor antagonist that has been developed for clinical testing as an antipsychotic in schizophrenic patients, has been tested in several animal models of the gating deficits in schizophrenia, including PPI. Previous studies have shown that M100907 blocks or reduces the disruptive effects of hallucinogenic $5-\mathrm{HT}_{2}$ agonists (e.g., DOI) and psychotomimetic NMDA antagonists (e.g., phencyclidine) on PPI. In the present paper, we report the results of three studies conducted to determine the effects of M100907 on apomorphine-induced disruption (one experiment) and isolation rearing-induced disruption of PPI in rats (two experiments). Results showed that M100907 failed to reduce the disruption of PPI caused by the dopamine agonist apomorphine. Nevertheless, M100907 partially reduced the disruption of PPI caused by isolation rearing. Thus, M100907 shows efficacy as a putative antipsychotic in nondopaminergic PPI models of the sensorimotor gating deficits in schizophrenia.

[Neuropsychopharmacology 21:S134-S142, 1999] (C) 1999 American College of Neuropsychopharmacology. Published by Elsevier Science Inc.
KEY WORDS: Schizophrenia; M100907; 5- $\mathrm{HT}_{2 \mathrm{~A}}$ receptor; Prepulse inhibition; Startle; Serotonin; Rat

Disruptions in measures of attention and cognition have been observed in patients diagnosed with schizophrenia. These deficits may be linked to an impairment in sensorimotor gating, such that intrusive stimuli are not properly filtered out (Grillon et al. 1990; McGhie and Chapman 1961; Venables 1960). In the acoustic startle paradigm, startle reactivity (i.e., startle magnitude) in response to high-intensity acoustic stimuli is measured and prepulse inhibition (PPI) is assessed. PPI re-

From the Department of Psychiatry (MAG, KK-T), University of California, San Diego, La Jolla, CA; and CNS Pharmacology (GBV), Schering-Plough Research Institute, Kenilworth, NJ.

Address correspondence to: Mark A. Geyer, Ph.D., Department of Psychiatry-0804, University of California, San Diego, 9500 Gilman Drive, La Jolla, CA 92093-0804.

Received July 12, 1999; revised September 15, 1999; accepted September 20, 1999. fers to the reduction in the startle response produced when a low-intensity, nonstartling stimulus (the prepulse) is presented shortly before the startle stimulus (Hoffman and Ison 1980). PPI provides an operational measure of sensorimotor gating that appears to be present in all mammals. Disruptions in PPI have been demonstrated in schizophrenic patients compared with healthy controls and patients diagnosed with mood disorders such as depression (Bolino et al. 1994; Braff et al. 1978, 1992; Cadenhead et al. 1997; Grillon et al. 1992; Weike et al. 1996). Deficits in schizophrenia patients do not simply result from generalized behavioral impairments or medications, because schizotypical patients who are not grossly psychotic or receiving antipsychotic medications exhibit similar PPI deficits (Cadenhead et al. 1993). Thus, patients with schizophrenia-spectrum disorders demonstrate dysfunctions in sensorimotor gating, as measured by disruptions in PPI.

A variety of pharmacologic (serotonergic, glutamater- 
gic, and dopaminergic) and nonpharmacologic (rearing in isolation) treatments disrupt PPI in animals and are used as models to characterize and identify antipsychotic drugs (Geyer et al. 1990). For example, the loss of sensorimotor gating observed in patients with schizophrenia has been mimicked in rats treated with the hallucinogenic 5- $\mathrm{HT}_{2}$-receptor agonist DOI (Padich et al. 1996; Sipes and Geyer 1994, 1995). Typical and atypical antipsychotics reduce the disruptive effect of DOI on PPI to varying degrees in different strains of rats (Padich et al. 1996; Sipes and Geyer 1994; Varty and Higgins 1995b). For example, the 5- $\mathrm{HT}_{2 \mathrm{~A} / \mathrm{C}}$ antagonist ketanserin, reduced the disruptive effects of DOI on PPI (Sipes and Geyer 1994). Further studies have found that the activity at $5-\mathrm{HT}_{2 \mathrm{~A}}$ receptors, but not $5-\mathrm{HT}_{2 \mathrm{C}}$ receptors, is important for the effect of ketanserin; the selective $5-\mathrm{HT}_{2 \mathrm{~A}}$ antagonist M100907, but not the $5-\mathrm{HT}_{2 \mathrm{C}}$ antagonist SDZ-SER-082, was effective in reversing the effects of DOI on PPI (Padich et al. 1996; Sipes and Geyer 1995). Additionally, M100907 reduced the effects of serotonin-releasing agents (MDMA and fenfluramine) on PPI (Padich et al. 1996). The effects of DOI and M100907 on PPI appear to be mediated by 5-HT $2 \mathrm{~A}$ receptors in the ventral pallidum (Sipes and Geyer 1997).

In addition to serotonergic systems, there is evidence that glutamatergic systems influence PPI. Phencyclidine (PCP) and other noncompetitive NMDA antagonists, such as ketamine and dizocilpine, produce effects in healthy subjects that are similar to the spectrum of symptoms and cognitive impairments associated with schizophrenia (Domino and Luby 1981; Javitt and Zukin 1991; Luby et al. 1959; Mansbach and Geyer 1991; Moghaddam 1994), and have been used to model psychosis in animals. NMDA antagonists also worsen symptoms in schizophrenic patients (Lahti et al. 1995a,b; Malhotra et al. 1997). PCP and dizocilpine have been shown to disrupt PPI in rats (Bakshi et al. 1994; Keith et al. 1991; Mansbach and Geyer 1989; Varty and Higgins 1995a; Swerdlow et al. 1996), and ketamine has been shown to disrupt PPI in humans (Karper et al. 1994). Thus, NMDA-receptor antagonist-induced disruption of PPI can be used as a model of schizophrenialike deficits in sensorimotor gating.

The disruptive effects of noncompetitive NMDA antagonists on PPI are not blocked by selective dopaminereceptor antagonists or most typical antipsychotics, but are reduced by atypical antipsychotics (e.g., clozapine, olanzapine, quetiapine), which have antagonistic activity at multiple receptor sites (Bakshi and Geyer 1995; Geyer et al. 1990; Hoffman et al. 1993; Hollister 1969; Keith et al. 1991; Swerdlow et al. 1996; Varty and Higgins 1995b). Several recent studies have tried to determine the specific receptors that underlie the ability of atypical antipsychotics to reduce the disruptive effects of NMDA antagonists on PPI.
The contributions of 5- $\mathrm{HT}_{2 \mathrm{~A}}$ and $5-\mathrm{HT}_{2 \mathrm{C}}$ receptors to the interaction between atypical antipsychotics and noncompetitive NMDA antagonists have recently been explored. Nonselective $5-\mathrm{HT}_{2}$ receptor antagonists (e.g., risperidone) have been shown to block the effects of noncompetitive NMDA antagonists in Wistar rats (Varty and Higgins 1995a,b), but not Sprague-Dawley rats (Bakshi et al. 1994; Swerdlow et al. 1996). Thus, there appears to be a strain difference in the ability of nonselective $5-\mathrm{HT}_{2}$-receptor antagonists to attenuate the effects of NMDA antagonists; previous studies have shown differences in PPI and its pharmacological manipulation among strains of rats (Rigdon 1990; Swerdlow et al. 1998a; Varty and Higgins 1994). M100907 significantly reduced the effects of dizocilpine on PPI in both strains of rats (Varty et al. 1999). In contrast, the 5-HT $2 \mathrm{C}$ antagonist SDZ-SER-082 completely failed to reduce the effects of dizocilpine (Varty et al. 1999). These results support the hypothesis that antagonism of $5-\mathrm{HT}_{2 \mathrm{C}}$ receptors, produced by nonselective $5-\mathrm{HT}_{2}$ receptor antagonists and SDZ-SER-082, interferes with a reversal of NMDA antagonist-induced disruptions of PPI in the Sprague-Dawley strain of rat (Bakshi et al. 1994). Together with previous reports (Varty and Higgins 1995a), these findings indicate that activity at $5-\mathrm{HT}_{2 \mathrm{~A}}$ receptors contributes to the efficacy of atypical antipsychotics in reducing the disruptive effects of NMDA antagonists on PPI.

Increasing dopaminergic transmission, such as with the direct dopamine agonist apomorphine, also disrupts PPI (Davis et al. 1990; Mansbach et al. 1988; Swerdlow et al. 1994). Apomorphine-induced disruption of PPI has been demonstrated to be due to the activation of $\mathrm{D}_{2}$-like dopaminergic receptors within the nucleus accumbens (Swerdlow et al. 1992). The effect of apomorphine on PPI can be reduced by the administration of both typical and atypical antipsychotics (Mansbach et al. 1988, 1998; Rasmussen et al. 1997; Rigdon and Viik 1991; Swerdlow et al. 1991, 1998a; Swerdlow and Geyer 1993). In contrast, several nondopaminergic compounds have proven ineffective in reducing the effects of apomorphine on PPI (Bakshi and Geyer 1997; Furuya et al. 1998; Rasmussen et al. 1997; Rigdon and Viik 1991). Therefore, the effects of apomorphine on PPI appear to be reduced, almost exclusively, by selective dopamine antagonists and multi-receptor antagonists (atypical antipsychotics). However, a serotonergic mechanism of action in the ability of the atypical antipsychotics to reverse apomorphine disruption of PPI has not been ruled out. Accordingly, in the present paper, we examined the effects of M100907 on apomorphine-induced disruption of PPI. We hypothesized that $5-\mathrm{HT}_{2 \mathrm{~A}}$-receptor antagonism would have no effect on the disruption of PPI produced by apomorphine.

We also have used developmental manipulations to produce a nonpharmacological model of the sensorimo- 
tor gating deficits of schizophrenia (Geyer et al. 1993; Varty and Higgins 1995b). Rat pups reared in isolation for 8 weeks from the time of weaning display deficits in PPI when tested in adulthood compared to socially reared rats (Geyer et al. 1993). This effect is developmentally specific because similar isolation of adult rats does not alter PPI (Wilkinson et al. 1994). Of potential therapeutic importance is the fact that PPI deficits produced by isolation rearing are reversed by both typical and atypical antipsychotics (Bakshi et al. 1998; Geyer et al. 1993; Varty and Higgins 1995b). This nonpharmacological method of inducing schizophrenia-like behavioral deficits has potential utility in the screening of novel antipsychotic drugs. Two experiments were conducted to examine the effects of M100907 on the disruption of PPI produced by isolation rearing in rats.

\section{METHODS}

\section{Subjects}

Apomorphine Challenge Experiment. Forty naive male Sprague-Dawley rats (Harlan Industries, San Diego, CA), weighing between 250 and $400 \mathrm{~g}$, were housed two to three per cage upon arrival. Animals were allowed to acclimate to housing conditions for approximately 1 week before the start of the experiment.

Isolation-Rearing Experiments. A total of 94 naive male Sprague-Dawley rats (Harlan, San Diego, CA), brought in as weaned 21-day-old pups, were used in the isolation-rearing studies; 31 rats were used in Experiment 1 and 63 rats were used in Experiment 2. In each experiment, pups were randomized to two groups: a socially reared group and an isolation-reared group. Socially reared pups were housed under normal social conditions (three per cage), whereas isolationreared pups were housed under isolated conditions (one per cage) for 8 weeks prior to the start of testing. All rats were housed in the same room and could hear, see, and smell other rats. Isolated rats received minimal handling; rats were handled once a week for cage cleaning.

All rats were housed in a temperature- and humidity-controlled room on a $12 \mathrm{~h}$ reversed light/dark cycle (lights off period 07.30-19.30 h). All testing occurred during the dark phase between 09.00 and $17.00 \mathrm{~h}$ (see Geyer and Swerdlow 1998 for a detailed description of experimental methods). Food and water were provided ad libitum.

\section{Drugs}

M100907, (R)-(+)- $\alpha$-(2,3-dimethoxyphenyl)-1-[2-(fluorophenyl)ethyl]-4-piperidinemethanol (Hoechst Marion Roussel, Frankfurt, Germany), was dissolved in a solu- tion of Tween 80 and distilled water. Apomorphine hydrochloride (Sigma Chemicals, St. Louis, MO) was dissolved in $0.1 \%$ ascorbic acid. All drugs were administered subcutaneously (SC) in a volume of $1 \mathrm{ml} / \mathrm{kg}$. Control animals were treated with the corresponding vehicle.

\section{Apparatus}

Four chambers were used to measure startle reactivity (SR-LAB, San Diego Instruments, San Diego, CA). Each chamber housed a Plexiglas cylinder $(9 \mathrm{~cm}$ in diameter) into which the rats were placed during each test session. Vibrations of the cylinder, caused by the wholebody startle response of the animal, were transduced into analog signals by a piezoelectric accelerometer attached to the platform. Stabilimeter readings were then rectified, digitized (0-4095), and stored by a microcomputer and interface assembly. A loudspeaker mounted $24 \mathrm{~cm}$ above the cylinder provided broadband background noise and auditory stimuli. The whole apparatus was housed within a ventilated, sound-attenuating chamber $(39 \times 38 \times 58 \mathrm{~cm})$. Presentations of acoustic stimuli were controlled by SR-LAB software and interface system. As previously described (Geyer and Swerdlow 1998; Mansbach et al. 1988), sound levels [dB(A) scale] and accelerometer sensitivities within each chamber were calibrated regularly and found to remain constant over the test period.

\section{Procedure}

Apomorphine Challenge Experiment. Four groups of rats $(n=10)$ were pretreated with either vehicle or 1.0 $\mathrm{mg} / \mathrm{kg}$ M100907. Twenty-five minutes later, rats were treated with either vehicle or $0.5 \mathrm{mg} / \mathrm{kg}$ apomorphine. Five minutes after the second injection, rats were placed in startle chambers for a 25-min PPI test session.

PPI test session consisted of a 5-min acclimatization period to a $65 \mathrm{~dB}$ background noise (continuous throughout the session), followed by a 20-min acoustic PPI test session. Five trial types were presented in this block: four $20 \mathrm{~ms}$ prepulse + pulse combinations that consisted of a $6 \mathrm{~dB}$ or $12 \mathrm{~dB}$ (above background) prepulse, each followed $100 \mathrm{~ms}$ or $300 \mathrm{~ms}$ later by a 40 $\mathrm{ms}, 120 \mathrm{~dB}$ startle pulse $(6 \mathrm{~dB}, 100 \mathrm{~ms} ; 12 \mathrm{~dB}, 100 \mathrm{~ms} ; 6$ $\mathrm{dB}, 300 \mathrm{~ms}$; and $12 \mathrm{~dB}, 300 \mathrm{~ms}$ ) and a $40 \mathrm{~ms}, 120 \mathrm{~dB}$ startle pulse alone (P120). Both the $100 \mathrm{~ms}$ and $300 \mathrm{~ms}$ interstimulus intervals (ISI) have been used to demonstrate drug and housing effects on PPI (Varty and Higgins 1995b; Varty et al. 1999). The trial types were presented in a pseudorandom order with an average inter-trial interval (ITI) of $15 \mathrm{~s}$. In addition, 5 P120 trials were presented at both the beginning and the end of the PPI test session, but these P120 trials were not used in the calculation of PPI. 
Isolation-Rearing Experiments. During Experiments 1 and 2, rat pups were housed either socially (three per cage) or in isolation (one per cage) for eight weeks before testing. In Experiment 1, four groups of rats $(n=$ $7-8)$ were administered either vehicle or $1.0 \mathrm{mg} / \mathrm{kg}$ M100907, $30 \mathrm{~min}$ before a 25-min PPI test session. One week later, rats were retested with the alternative treatment in a within-subjects design. As in the apomorphine experiment, PPI test sessions consisted of a 5-min acclimatization period to a $65-\mathrm{dB}$ background noise (continuous throughout the session), followed by a 20min acoustic PPI test session. During the acoustic PPI session, five trial types were presented: a $40 \mathrm{~ms}, 120 \mathrm{~dB}$ startle pulse (P120); and one of three $20 \mathrm{~ms}$ prepulses of 3,6 , or $12 \mathrm{~dB}$ above background, followed $100 \mathrm{~ms}$ later by the pulse ( $3 \mathrm{~dB}, 100 \mathrm{~ms} ; 6 \mathrm{~dB}, 100 \mathrm{~ms}$; and $12 \mathrm{~dB}, 100$ $\mathrm{ms})$. Again, trial types were presented in a pseudorandom order with an average ITI of $15 \mathrm{~s}$. In addition, 5 P120 trials were presented at both the beginning and the end of the acoustic test session.

In Experiment 2, a separate cohort of four groups of rats $(n=14-16)$ were administered either vehicle or 1.0 $\mathrm{mg} / \mathrm{kg}$ M100907 $30 \mathrm{~min}$ before a 25-min PPI test session in a between-subjects design. The PPI session of Experiment 2 was the same type of session employed in the apomorphine experiment described above.

\section{Statistical Analysis}

The magnitude of PPI (\% PPI) was determined according to the following formula: \% PPI $=[100-(\{$ startle magnitude on prepulse + pulse trials/startle magnitude on pulse-alone trials $\} \times 100$ )], such that a $0 \%$ value indicated no difference between the responses to prepulse + pulse trials and pulse alone trials (i.e., no PPI) (Geyer and Swerdlow 1998).

Apomorphine Challenge Experiment. Percent PPI data were analyzed using a two-way analysis of variance (ANOVA) with prepulse intensity and ISI as withinsubjects factors, and pretreatment and treatment as the between-subjects factors. Mean \% PPI was analyzed using two-way ANOVA with pretreatment and treatment as between-subjects factors.

Isolation-Rearing Experiments. Our a priori hypothesis that M100907 would reverse isolation-induced PPI deficits, based on past evidence that isolation rearing disrupts PPI and that M100907 does not increase PPI on its own, led us to perform separate post hoc ANOVAs of both data sets. Isolation-rearing PPI deficits were tested by performing a one-way ANOVA for housing effect in vehicle-treated or M100907-treated rats. M100907 antagonism of isolation rearing-induced PPI deficits was tested by performing a one-way ANOVA for drug effect in Isolated or Social rats. F-values are described only for significant effects. When main effects

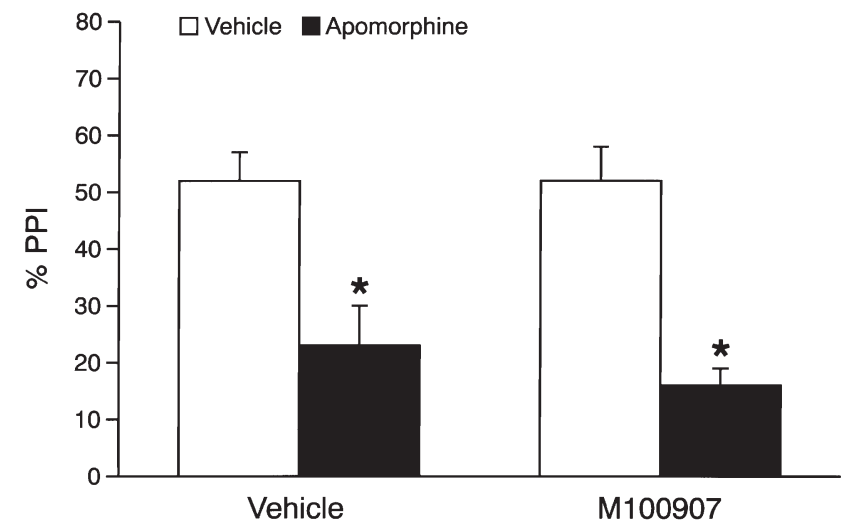

Figure 1. Effect of M100907 pretreatment and apomorphine treatment on prepulse inhibition (PPI) in rats. Apomorphine $(0.5 \mathrm{mg} / \mathrm{kg}, \mathrm{SC})$ treatment significantly disrupted mean \% PPI. Pretreatment with $1.0 \mathrm{mg} / \mathrm{kg}$ M100907 (SC) had no effect on PPI by itself and failed to reduce the effects of apomorphine on PPI. Data are presented as group means \pm SEM for the entire startle session. * Significantly different from Vehicle/Vehicle group (Tukey post hocs).

were significant, post hoc analyses were conducted using Tukey's protected-t with a 0.05 level of significance.

\section{RESULTS}

\section{Apomorphine Challenge Experiment}

Apomorphine produced a disruption of PPI in both vehicle- and M100907-pretreated rats as revealed by a significant main effect of apomorphine treatment $[\mathrm{F}(1,36)=$ 34.57]. Pretreatment with M100907 had no effect on disruption of PPI by apomorphine; there was neither a main effect of M100907 pretreatment nor an interaction between M100907 and apomorphine. There was a significant interaction of apomorphine treatment with ISI level $[\mathrm{F}(1,36)=4.81]$, but no other interactions. Because of the significant interaction with ISI, two-way ANOVAs for each ISI/Intensity combination were performed. While each combination demonstrated a significant main effect of apomorphine treatment (data not shown), no significant interactions were found. There was no effect of drug on startle magnitude.

Mean \% PPI data for the apomorphine challenge experiment are presented in Figure 1. Post hoc comparisons confirmed that the Vehicle/Apomorphine and the M100907/Apomorphine groups were significantly different from the Vehicle/Vehicle group.

\section{Isolation-Rearing Experiments}

Isolation rearing disrupted PPI in most prepulse conditions, as revealed by a significant effect of housing in vehicle-treated rats in Experiment $1[\mathrm{~F}(1,28)=7.19]$ and Experiment $2[\mathrm{~F}(1,29)=4.92]$. There was a significant 
Table 1. Effect of Pretreatment with either Vehicle or 1.0 $\mathrm{mg} / \mathrm{kg}$ M100907 on \% PPI in Rats Reared Socially or in Isolation

\begin{tabular}{llllll}
\hline & \multicolumn{2}{c}{ Vehicle } & & \multicolumn{2}{c}{ M100907 } \\
\cline { 2 - 3 } Rearing Condition & Social & Isolated & & Social & Isolated \\
\hline Experiment 1 & & & & \\
$3 \mathrm{~dB}, 100 \mathrm{~ms}$ & $51 \pm 3$ & $37 \pm 5^{\mathrm{a}}$ & & $50 \pm 3$ & $44 \pm 5$ \\
$\quad 6 \mathrm{~dB}, 100 \mathrm{~ms}$ & $62 \pm 3$ & $51 \pm 4^{\mathrm{a}}$ & & $72 \pm 2$ & $61 \pm 4$ \\
$\quad 12 \mathrm{~dB}, 100 \mathrm{~ms}$ & $76 \pm 3$ & $65 \pm 4^{\mathrm{a}}$ & & $80 \pm 2$ & $73 \pm 3$ \\
Experiment 2 & & & & \\
$6 \mathrm{~dB}, 100 \mathrm{~ms}$ & $52 \pm 5$ & $40 \pm 5$ & & $55 \pm 5$ & $48 \pm 5$ \\
$12 \mathrm{~dB}, 100 \mathrm{~ms}$ & $66 \pm 4$ & $53 \pm 7$ & & $74 \pm 3$ & $70 \pm 3^{\mathrm{b}}$ \\
$6 \mathrm{~dB}, 300 \mathrm{~ms}$ & $42 \pm 4$ & $22 \pm 7^{\mathrm{a}}$ & & $46 \pm 4$ & $47 \pm 4^{\mathrm{b}}$ \\
$12 \mathrm{~dB}, 300 \mathrm{~ms}$ & $57 \pm 4$ & $49 \pm 5$ & & $64 \pm 4$ & $68 \pm 3^{\mathrm{b}}$ \\
\hline
\end{tabular}

aSignificantly different from Social/Vehicle group.

bSignificantly different from Isolated/Vehicle group.

effect of housing in vehicle-treated rats in Experiment 1 $[\mathrm{F}(1,14)=7.37]$ on startle magnitude, but there was no effect on startle in Experiment 2. Thus, the PPI deficits produced by isolation rearing are independent of any effects on startle magnitude. Specific comparisons revealed that the Social/Vehicle group differed from the Isolated/ Vehicle group for all conditions in Experiment 1 and in the $6 \mathrm{~dB} 300 \mathrm{~ms}$ condition in Experiment 2 (Table 1).

M100907 partially reversed the isolation rearinginduced disruption of PPI, as revealed by a significant effect of drug in isolated rats in Experiment $1[\mathrm{~F}(1,15)=$ 5.67] and Experiment $2[\mathrm{~F}(1,30)=8.42]$, but not in socially reared rats in either experiment. Additionally, there was no significant effect of housing in M100907treated rats in either Experiment 1 or 2. Specific comparisons revealed that there was a significant difference between the Isolated/Vehicle and Isolated/M100907 groups for the $12 \mathrm{~dB} 100 \mathrm{~ms}, 6 \mathrm{~dB} 300 \mathrm{~ms}$, and the $12 \mathrm{~dB}$ $300 \mathrm{~ms}$ conditions in Experiment 2, but not in any specific condition in Experiment 1. There was no significant main effect of M100907 in socially reared rats in either experiment. Nevertheless, post hoc comparisons revealed a significant difference between the Social/Vehicle and Social/M100907 groups for the 6 dB $100 \mathrm{~ms}$ condition in Experiment 1 (Table 1). As shown in Figure 2 , these effects were replicated in the mean \% PPI data.

\section{DISCUSSION}

The present experiments demonstrated two new findings regarding the effects of the putative antipsychotic M100907 on PPI in rats. First, M100907 is inactive in the primary dopaminergic model of sensorimotor gating deficits in schizophrenia. Specifically, M100907 failed to diminish the PPI-disruptive effects of apomorphine and also had no effect on PPI by itself. Second, M100907
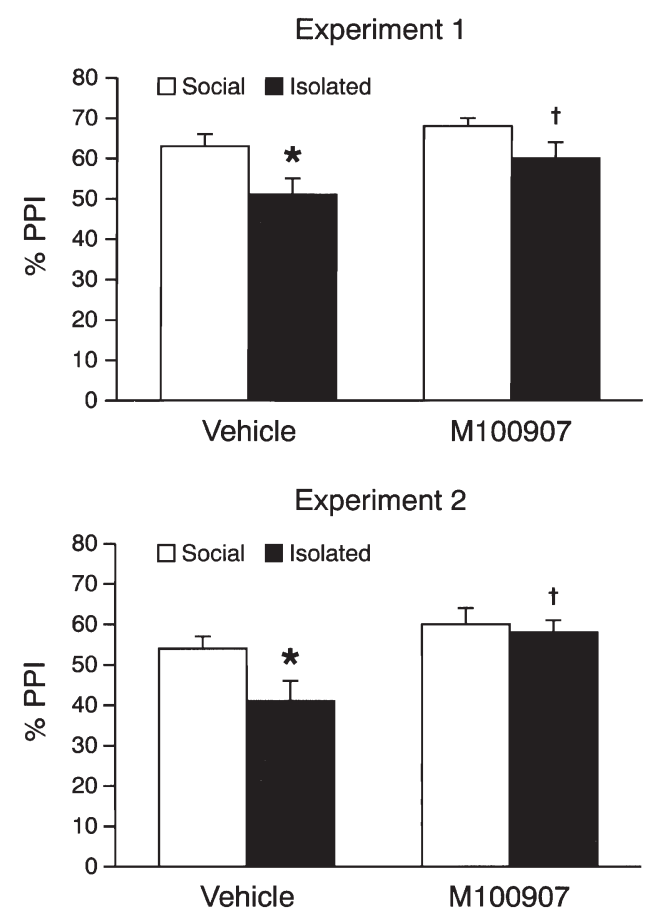

Figure 2. Effect of pretreatment with M100907 on mean \% PPI in rats reared socially (three per cage) or in isolation (one per cage). Eight weeks later, rats were treated with either saline or $1.0 \mathrm{mg} / \mathrm{kg}$ M100907 (SC) and tested for PPI. Isolation-reared rats show disrupted PPI. M100907 pretreatment had no effect on PPI by itself, but significantly reduced isolation rearing-induced disruption of PPI. The upper panel depicts results from Experiment 1 and the lower panel depicts the results from Experiment 2 (data from a different cohort of animals tested in a different PPI test session). * Significant effect of housing in vehicle-treated rats. ${ }^{\dagger}$ Significant effect of drug in isolated rats.

partially reversed the disruption of PPI observed in isolation-reared rats, while having no significant effects in socially reared rats.

There are several variants of the PPI paradigm that putatively model the sensorimotor gating deficits exhibited by patients with schizophrenia. Attempts to model certain aspects of psychoses present in the schizophrenia-spectrum disorders include disruption of PPI in rats by the administration of $5-\mathrm{HT}_{2}$-receptor agonists, NMDA-receptor antagonists, and as shown in the present studies, administration of dopamine agonists and isolation rearing. The validity of these models has been assessed by examining the effects of various antipsychotic agents.

Drugs that increase dopamine transmission in humans produce a psychotic state similar to that observed during acute psychotic episodes in schizophrenic patients. As previously reported (Mansbach et al. 1988) and replicated in the present paper, dopamine agonists such as apomorphine disrupt PPI in rats. Selective 
dopamine antagonists, as well as typical and atypical antipsychotics, reduce the apomorphine-induced disruption of PPI (Mansbach et al. 1988, 1998; Rasmussen et al. 1997; Swerdlow et al. 1991, 1994; Swerdlow and Geyer 1993; Varty and Higgins 1995b). In contrast, the current experiment demonstrated that the selective $5-\mathrm{HT}_{2 \mathrm{~A}}$-receptor antagonist M100907 does not attenuate the effects of apomorphine on PPI. Thus, dopamine agonism appears to be a good model of schizophrenia-like disruptions in PPI, but may not be the optimal paradigm for screening the new generation of potential atypical antipsychotics such as M100907, which have little activity at dopamine receptors.

In two of the present studies, isolation rearing produced deficits in PPI, confirming previous reports (Geyer et al. 1993; Varty and Higgins 1995b). These deficits were significant in the vehicle-treated rats in both experiments, but were significantly diminished in the M100907-treated rats. Thus, M100907 partially reversed the deficit in PPI produced by isolation rearing when tested either in a between-subjects or a within-subjects design. Although the trend for M100907 treatment to increase PPI in socially reared rats appears to have prevented the demonstration of a significant interaction between housing and drug treatment, post hoc comparisons based on the a priori hypothesis confirmed that M100907 significantly increased PPI in isolation-reared rats but not in socially reared rats. A similar trend for an M100907-induced increase in PPI has been seen in previous studies, but has never reached significance when M100907 was administered systemically (Sipes and Geyer 1995). Indeed, M100907 alone produced no increase in PPI in the apomorphine experiment, indicating that this tendency is inconsistent. Intra-ventral pallidal administration of M100907, however, has been shown to produce a significant increase in PPI (Sipes and Geyer 1997). The present studies indicate that M100907 treatment reduces the effects of isolation rearing on PPI. Furthermore, as both typical and atypical antipsychotics attenuate the effects of isolation rearing, isolation rearing seems to be a good model of schizophrenia-like behavioral deficits in PPI and may have utility for screening putative atypical antipsychotics.

The serotonin system has been implicated in the psychopathology of schizophrenia. Early studies demonstrated altered levels of serotonin and its metabolites in the cerebrospinal fluid, and decreased densities of serotonin receptors in postmortem brain tissue, of schizophrenic patients (Abi-Dargham et al. 1997; Breier 1995; Busatto and Kerwin 1997; Gurevich and Joyce 1997; Harrison and Burnet 1997; Issa et al. 1994; Joyce et al. 1993; Nyberg and Farde 1997). Although there have been problems with replication and confounding factors in many of these studies, the hypothesis that alterations of serotonergic transmission could be involved in schizophrenia was supported by the discovery that atypical antipsychotic drugs have $5-\mathrm{HT}_{2 \mathrm{~A}}$-receptor antagonist activity (Goyer et al. 1996; Meltzer 1995a,b).

Serotonin 5- $\mathrm{HT}_{2}$-receptor agonists (e.g., DOI), known as classical hallucinogenic drugs, produce a limited number of effects in humans that appear similar to the symptoms of schizophrenia. $5-\mathrm{HT}_{2}$-receptor agonists produce disruptions in PPI in animals (Padich et al. 1996; Sipes and Geyer 1994, 1995). Some typical and atypical antipsychotics reduce these effects, while others do not (Padich et al. 1996; Sipes and Geyer 1994; Varty and Higgins 1995b). Nonselective 5- $\mathrm{HT}_{2}$-receptor antagonists that do not appear to be efficacious as antipsychotics, however, do attenuate these effects (Sipes and Geyer 1994). In addition, the selective $5-\mathrm{HT}_{2 \mathrm{~A}}$-receptor antagonist M100907 robustly reduced the effects of DOI on PPI (Padich et al. 1996; Sipes and Geyer 1995). Thus, nonselective $5-\mathrm{HT}_{2}$-receptor agonism produces schizophrenia-like PPI deficits in rats that are sensitive to $5-\mathrm{HT}_{2 \mathrm{~A}}$ antagonists and serotonergic atypical antipsychotics, but less sensitive to dopaminergic typical antipsychotics.

In humans, noncompetitive NMDA-receptor antagonists, such as PCP or ketamine, can produce psychotic symptoms similar to those observed in schizophrenic patients (Javitt and Zukin 1991; Luby et al. 1959). These compounds also disrupt PPI in animals (Bakshi et al. 1994; Keith et al. 1991; Mansbach and Geyer 1989, 1991; Varty and Higgins 1995a) and humans (Karper et al. 1994). A number of atypical antipsychotics, including clozapine, olanzapine, and quetiapine, reduce the effects NMDA antagonists on PPI (Bakshi et al. 1994; Bakshi and Geyer 1995; Swerdlow et al. 1996), whereas most typical antipsychotics are ineffective (Furuya et al. 1998; Geyer et al. 1990; Johansson et al. 1994; Keith et al. 1991; Swerdlow et al. 1996, 1998b; Varty and Higgins 1995b). With regard to serotonin/glutamate interactions, nonselective $5-\mathrm{HT}_{2}$-receptor antagonists are effective in the NMDA antagonist PPI model only to a limited extent and in certain rat strains (Bakshi et al. 1994; Varty et al. 1999; Varty and Higgins 1995a). In contrast, M100907 pretreatment markedly reduced the PPI-disruptive effects of dizocilpine in two different strains of rats (Varty et al. 1999). Thus, noncompetitive NMDA receptor antagonism is a more promising candidate for modeling symptoms of sensorimotor gating deficits in schizophrenia and as a method for screening novel antipsychotics.

In conclusion, based on nondopaminergic models of deficient PPI, the selective $5-\mathrm{HT}_{2 \mathrm{~A}}$-receptor antagonist M100907 appears to have potential utility as an atypical antipsychotic. Although M100907 proved to be inactive in the apomorphine model of disrupted PPI, it is effective in reducing deficits in PPI produced by hallucinogenic $5-\mathrm{HT}_{2 \mathrm{~A}}$ agonists, psychotomimetic NMDA antagonists, or isolation rearing. If the results of Phase III clinical trials of M100907 support the efficacy of this drug as a treatment for schizophrenia, the pharmaco- 
logic and non-pharmacologic PPI models of schizophrenia will be supported in their utility to screen novel antipsychotic drugs.

\section{ACKNOWLEDGMENTS}

This work was supported by grant R01-MH52885 from the National Institute of Mental Health (NIMH), by funding from the Department of Veteran Affairs through the VISN $22 \mathrm{MI}-$ RECC (Mental Illness, Research, Education and Clinical Center), and by an unrestricted educational grant from Hoechst Marion Roussel. Mark Geyer has an equity interest in San Diego Instruments, Inc. and was supported by Research Scientist Award K05-MH01228 from NIMH. The authors wish to thank Hoechst Marion Roussel for their generous gift of the M100907. We also thank Virginia Lehmann-Masten, Darlene Giracello, Barbara Carasso, and Arturo Solis for their excellent assistance throughout these studies.

\section{REFERENCES}

Abi-Dargham A, Laruelle M, Aghajanian GK, Charney D, Krystal J (1997): The role of serotonin in the pathophysiology and treatment of schizophrenia. J Neuropsychiatry Clin Neurosci 9:1-17

Bakshi VP, Geyer MA (1995): Antagonism of phencyclidineinduced deficits in prepulse inhibition by the putative atypical antipsychotic olanzapine. Psychopharmacology 122:198-201

Bakshi VP, Geyer MA (1997): Phencyclidine-induced deficits in prepulse inhibition of startle are blocked by prazosin, an alpha-1 noradrenergic antagonist. J Pharmacol Exp Ther 283:666-674

Bakshi VP, Swerdlow NR, Braff DL, Geyer MA (1998): Reversal of isolation rearing-induced deficits in prepulse inhibition by Seroquel and olanzapine. Biol Psychiatry 43:436-445

Bakshi VP, Swerdlow NR, Geyer MA (1994): Clozapine antagonizes phencyclidine-induced deficits in sensorimotor gating of the startle response. J Pharmacol Exp Ther 271:787-794

Bolino F, di Michele V, di Cicco L, Manna V, Daneluzzo E, Cassachia M (1994): Sensorimotor gating and habituation evoked by electrocutaneous stimulation in schizophrenia. Biol Psychiatry 36:670-679

Braff DL, Grillon C, Geyer MA (1992): Gating and habituation of the startle reflex in schizophrenic patients. Arch Gen Psychiatry 49:206-215

Braff D, Stone C, Callaway E, Geyer M, Glick I, Bali L (1978): Prestimulus effects on human startle reflex in normals and schizophrenics. Psychophysiology 15:339-343

Breier A (1995): Serotonin, schizophrenia and antipsychotic drug action. Schizophr Res 14:187-202

Busatto GF, Kerwin RW (1997): Perspectives on the role of serotonergic mechanisms in the pharmacology of schizophrenia. J Psychopharmacol 11:3-12

Cadenhead KS, Geyer MA, Braff DL (1993): Impaired startle prepulse inhibition and habituation in patients with schizotypal personality disorder. Am J Psychiatry 150:1862-1867

Cadenhead KS, Geyer MA, Butler RW, Perry W, Sprock J, Braff DL (1997): Information processing deficits of schizophrenia patients: Relationship to clinical ratings, gender and medication status. Schizophr Res 28:51-62

Davis M, Mansbach RS, Swerdlow NR, Campeau S, Braff DL, Geyer MA (1990): Apomorphine disrupts the inhibition of acoustic startle induced by weak prepulses in rats. Psychopharmacology 102:1-4

Domino EF, Luby ED (1981): Abnormal mental states induced by phencyclidine as a model of schizophrenia. In Domino EF (ed), PCP (Phencyclidine): Historical and Current Perspectives. Ann Arbor, MI, NPP Books, pp $400-418$

Furuya Y, Kagaya T, Nishizawa Y, Ogura H (1998): Differential effects of the strychnine-insensitive glycine site antagonist + -HA-966 on the hyperactivity and the disruption of prepulse inhibition induced by phencyclidine in rats. Brain Res 781:227-235

Geyer MA, Swerdlow NR (1998): Measurement of startle response, prepulse inhibition, and habituation. In Crawley JN, Gerfen CR, McKay R, Rogawski MA, Sibley DR, Skolnick P (eds), Current Protocols in Neuroscience. New York, John Wiley \& Sons, pp 8.7.1-8.7.15

Geyer MA, Swerdlow NR, Mansbach RS, Braff DL (1990): Startle response models of sensorimotor gating and habituation deficits in schizophrenia. Brain Res Bull 25:485-498

Geyer MA, Wilkinson LS, Humby T, Robbins TW (1993): Isolation rearing of rats produces a deficit in prepulse inhibition of acoustic startle similar to that in schizophrenia. Biol Psychiatry 34:361-372

Goyer PF, Berridge MS, Morris ED, Semple WE, ComptonToth BA, Schulz SC, Wong DF, Miraldi F, Meltzer HY (1996): PET measurement of neuroreceptor occupancy by typical and atypical neuroleptics. J Nucl Med 37:1122-1127

Grillon C, Ameli R, Charney DS, Krystal J, Braff D (1992): Startle gating deficits occur across prepulse intensities in schizophrenic patients. Biol Psychiatry 32:939-943

Grillon C, Courchesne E, Ameli R, Geyer MA, Braff DL (1990): Increased distractibility in schizophrenic patients: Electrophysiological and behavioral evidence. Arch Gen Psychiatry 47:171-179

Gurevich EV, Joyce JN (1997): Alterations in the cortical serotonergic system in schizophrenia: A postmortem study. Biol Psychiatry 42:529-545

Harrison PJ, Burnet PW (1997): The 5-HT2A (serotonin2A) receptor gene in the aetiology, pathophysiology and pharmacotherapy of schizophrenia. J Psychopharmacol 11:18-20

Hoffman DC, Donovan H, Cassella JV (1993): The effects of haloperidol and clozapine on the disruption of sensorimotor gating induced by the noncompetitive glutamate antagonist MK-801. Psychopharmacology 111:339-344

Hoffman HS, Ison JR (1980): Reflex modification in the domain of startle: I. Some empirical findings and their implication for how the nervous system processes sensory input. Psychol Rev 87:175-189 
Hollister LE (1969): Steroids and moods: Correlations in schizophrenics and subjects treated with lysergic acid diethylamide (LSD), mescaline, tetrahydrocannabinol, and synhexyl. J Clin Pharmacol J New Drugs 9:24-29

Issa F, Gerhardt GA, Bartko JJ, Suddath RL, Lynch M, Gamache PH, Freedman R, Wyatt RJ, Kirch DG (1994): A multidimensional approach to analysis of cerebrospinal fluid biogenic amines in schizophrenia. I. Comparisons with healthy control subjects and neuroleptic-treated/ unmedicated pairs analyses. Psychiatry Res 52:237-249

Javitt DC, Zukin SR (1991): Recent advances in the phencyclidine model of schizophrenia. Am J Psychiatry 10:1301-1308

Johansson C, Jackson DM, Svensson L (1994): The atypical antipsychotic, remoxipride, blocks phencyclidineinduced disruption of prepulse inhibition in the rat. Psychopharmacology 116:437-442

Joyce JN, Shane A, Lexow N, Winokur A, Casanova MF, Kleinman JE (1993): Serotonin uptake sites and serotonin receptors are altered in the limbic system of schizophrenics. Neuropsychopharmacology 8:315-336

Karper LP, Grillon C, Charney DS, Krystal JH (1994): The effect of ketamine on pre-pulse inhibition and attention. Proc Am Coll Neuropsychopharmacol:124

Keith VA, Mansbach RS, Geyer MA (1991): Failure of haloperidol to block the effects of phencyclidine and dizocilpine on acoustic startle prepulse inhibition. Biol Psychiatry 30:557-566

Lahti AC, Holcomb HH, Medoff DR, Tamminga CA (1995a): Ketamine activates psychosis and alters limbic blood flow in schizophrenia. NeuroReport 6:869-872

Lahti AC, Koffel B, LaPorte D, Tamminga CA (1995b): Subanesthetic doses of ketamine stimulate psychosis in schizophrenia. Neuropsychopharmacology 13:9-19

Luby ED, Cohen BD, Rosenbaum G, Gottlieb JS, Kelly R (1959): Study of a new schizophrenomimetic drug-Sernyl. AMA Arch Neurol Psychiatry 81:363-369

Malhotra AK, Pinals DA, Adler CM, Elman I, Clifton A, Pickar D, Breier A (1997): Ketamine-induced exacerbation of psychotic symptoms and cognitive impairment in neuroleptic-free schizophrenics. Neuropsychopharmacology 17:41-50

Mansbach RS, Brooks EW, Sanner MA, Zorn SH (1998): Selective dopamine D4 receptor antagonists reverse apomorphine-induced blockade of prepulse inhibition. Psychopharmacology 135:194-200

Mansbach RS, Geyer MA (1989): Effects of phencyclidine and phencyclidine biologs on sensorimotor gating in the rat. Neuropsychopharmacology 2:299-308

Mansbach RS, Geyer MA (1991): Parametric determinants in pre-stimulus modification of acoustic startle: Interaction with ketamine. Psychopharmacology 105:162-168

Mansbach RS, Geyer MA, Braff DL (1988): Dopaminergic stimulation disrupts sensorimotor gating in the rat. Psychopharmacology 94:507-514

McGhie A, Chapman J (1961): Disorders of attention and perception in early schizophrenia. Br J Med Psychol 34:102-116

Meltzer HY (1995b): Role of serotonin in the action of atypical antipsychotic drugs. Clin Neurosci 3:64-75
Meltzer HY (1995a): The role of serotonin in schizophrenia and the place of serotonin-dopamine antagonist antipsychotics. J Clin Psychopharmacol 15:2S-3S

Moghaddam B (1994): Recent basic findings in support of excitatory amino acid hypotheses of schizophrenia. Prog Neuropsychopharmacol Biol Psychiatry 18:859-870

Nyberg S, Farde L (1997): The relevance of serotonergic mechanisms in the treatment of schizophrenia has not been confirmed. J Psychopharmacol 11:13-14

Padich RA, McCloskey TC, Kehne JH (1996): 5-HT modulation of auditory and visual sensorimotor gating. II. Effects of the 5- $\mathrm{HT}_{2 \mathrm{~A}}$ antagonist MDL 100,907 on disruption of sound and light prepulse inhibition produced by 5-HT agonists in Wistar rats. Psychopharmacology 124:107-116

Rasmussen K, Gates MR, Burger JE, Czachura JF (1997): The novel atypical antipsychotic olanzapine, but not the CCK-B antagonist LY288513, blocks apomorphineinduced disruption of pre-pulse inhibition. Neurosci Lett 222:61-64

Rigdon GC (1990): Differential effects of apomorphine on prepulse inhibition of acoustic startle reflex in two rat strains. Psychopharmacology 102:419-421

Rigdon GC, Viik K (1991): Prepulse inhibition as a screening test for potential antipsychotics. Drug Dev Res 23:91-99

Sipes TA, Geyer MA (1994): Multiple serotonin receptor subtypes modulate prepulse inhibition of the startle response in rats. Neuropharmacology 33:441-448

Sipes TE, Geyer MA (1995): DOI disruption of prepulse inhibition of startle in the rat is mediated by $5-\mathrm{HT}_{2 \mathrm{~A}}$ and not by $5-\mathrm{HT}_{2 \mathrm{C}}$ receptors. Behav Pharmacol 6:839-842

Sipes TE, Geyer MA (1997): DOI disrupts prepulse inhibition of startle in rats via $5-\mathrm{HT}_{2 \mathrm{~A}}$ receptors in the ventral pallidum. Brain Res 761:97-104

Swerdlow NR, Bakshi VP, Geyer MA (1996): Seroquel restores sensorimotor gating in phencyclidine-treated rats. J Pharmacol Exp Ther 279:1290-1299

Swerdlow NR, Bakshi VP, Waikar M, Taaid N, Geyer MA (1998b): Seroquel, clozapine and chlorpromazine, but not haloperidol, restore sensorimotor gating in ketamine treated rats. Psychopharmacology 140:75-80

Swerdlow NR, Caine SB, Geyer MA (1992): Regionally selective effects of intracerebral dopamine infusion on sensorimotor gating of the startle reflex in rats. Psychopharmacology 108:189-195

Swerdlow NR, Geyer MA (1993): Clozapine and haloperidol in an animal model of sensorimotor gating deficits in schizophrenia. Pharmacol Biochem Behav 44:741-744

Swerdlow NR, Keith VA, Braff DL, Geyer MA (1991): Effects of spiperone, raclopride, SCH 23390 and clozapine on apomorphine inhibition of sensorimotor gating of the startle response in the rat. J Pharmacol Exp Ther 256:530-536

Swerdlow NR, Varty GB, Geyer MA (1998a): Discrepant findings of clozapine effects on prepulse inhibition of startle: Is it the route or the rat? Neuropsychopharmacology 18:50-56

Swerdlow NR, Zisook D, Taaid N (1994): Seroquel ICI 204,636 restores prepulse inhibition of acoustic startle in apomorphine-treated rats: Similarities to clozapine. Psychopharmacology 114:675-678 
Varty GB, Bakshi VP, Geyer MA (1999): M100907, a serotonin $5-\mathrm{HT}_{2 \mathrm{~A}}$ receptor antagonist and putative antipsychotic, blocks dizocilpine-induced prepulse inhibition deficits in Sprague-Dawley and Wistar rats. Neuropsychopharmacology 20:311-321

Varty GB, Higgins GA (1994): Differences between three rat strains in sensitivity to prepulse inhibition of an acoustic startle response: influence of apomorphine and phencyclidine pretreatment. J Psychopharmacol 8:148-156

Varty GB, Higgins GA (1995b): Examination of druginduced and isolation-induced disruptions of prepulse inhibition as models to screen antipsychotic drugs. Psychopharmacology 122:15-26

Varty GB, Higgins GA (1995a): Reversal of dizocilpine- induced disruption of prepulse inhibition of an acoustic startle response by the 5-HT2 receptor antagonist ketanserin. Eur J Pharmacol 287:201-205

Venables PH (1960): The effect of auditory and visual stimulation on the skin potential responses of schizophrenics. Brain 83:77-92

Weike A, Globisch J, Hamm A, Bauer U (1996): Prepulse inhibition and habituation of skin conductance responses in schizophrenics: Neuroleptic drug effects. Psychophysiology 33:S88

Wilkinson LS, Killcross SS, Humby T, Hall FS, Geyer MA, Robbins TW (1994): Social isolation in the rat produces developmentally specific deficits in prepulse inhibition of the acoustic startle response without disrupting latent inhibition. Neuropsychopharmacology 10:61-72 